\title{
Article \\ A Comprehensive Virtual Synchronous Generator Control Strategy for Harmonic and Imbalance Voltage Suppression of Multi-Inverter Parallel Microgrid
}

\author{
Yannan Dong ${ }^{1}$, Shaohua Ma ${ }^{1, *}$, Zijiao Han ${ }^{1,2}$, Henan Dong ${ }^{3}$ and Xiangjun Li $^{4}$ (D) \\ 1 Institute of Electrical Engineering, Shenyang University of Technology, Shenyang 110870, China; \\ dongyn1992@gmail.com (Y.D.); thuwhatever@163.com (Z.H.) \\ 2 Liaoning Electric Power Company, State Grid Corporation of China, Shenyang 110004, China \\ 3 Liaoning Electric Power Company Electric Power Research Institute, State Grid Corporation of China, \\ Shenyang 110006, China; $13555878500 @ 163 . c o m$ \\ 4 State Key Laboratory of Control and Operation of Renewable Energy and Storage Systems, \\ China Electric Power Research Institute, Beijing 100192, China; li_xiangjun@126.com \\ * Correspondence: mash_dq@sut.edu.cn
}

\section{check for}

updates

Citation: Dong, Y.; Ma, S.; Han, Z.; Dong, H.; Li, X. A Comprehensive Virtual Synchronous Generator Control Strategy for Harmonic and Imbalance Voltage Suppression of Multi-Inverter Parallel Microgrid. Electronics 2022, 11, 492. https:// doi.org/10.3390/electronics11030492 Academic Editors: Dumitru Popescu, Haoping Wang, Severus C. Olteanu and Ciprian Lupu

Received: 18 January 2022 Accepted: 5 February 2022 Published: 8 February 2022

Publisher's Note: MDPI stays neutral with regard to jurisdictional claims in published maps and institutional affiliations.

Copyright: () 2022 by the authors Licensee MDPI, Basel, Switzerland. This article is an open access article distributed under the terms and conditions of the Creative Commons Attribution (CC BY) license (https:// creativecommons.org/licenses/by/ $4.0 /)$.

\begin{abstract}
To reduce the impact of the imbalance of mixed non-linear loads on an inverter voltage output in the microgrid, we improve the disadvantage of the lack of damping and inertia for traditional droop control. This paper proposes a comprehensive virtual synchronous generator (VSG) control strategy for harmonic suppression and imbalance suppression of a multi-inverter parallel microgrid. On one hand, an improved VSG control strategy is proposed to increase the damping and inertia of distributed generations (DGs) in the microgrid, and secondary control is introduced to improve system stability. On the other hand, the frequency division suppression control strategy is used to eliminate the influence of harmonics, and the negative sequence component is compensated to eliminate the influence of imbalance. Then small-signal analysis is used for analysis of the stability of the strategy. Finally, we verify the comprehensive control strategy proposed in this paper through experiments. The experimental results suggest a significant improvement on the voltage, frequency, power optimization, handling of non-linear load and capacity distribution precision, as well as providing inertia support for the system.
\end{abstract}

Keywords: harmonic suppression; imbalance suppression; microgrid; imbalance mixed non-linear loads; virtual synchronous generator

\section{Introduction}

Scholars recently proposed that the microgrid has become an essential form of multiple DGs integration, which is an important complementary of a traditional power network via inverters [1,2]. The microgrid has been studied extensively in its structures, modeling and operation [3], stability analysis and enhancement [4], power quality improvement [5], and other issues, presently.

The existing inverter control strategy can be adopted when these DGs are connected to the microgrid. However, as the DGs scale gradually increases, the conventional control strategy may fail to work properly. Therefore, scholars proposed a VSG technology with the characteristics of self-balancing feasibility, rotational inertia and droop characteristics of a synchronous machine, that can be used in DGs and microgrid inverter control to improve system stability [6-10]. Ref. [11] compared the dynamic characteristics of droop control and VSG control, then concluded that droop control is a special form of VSG control $(\mathrm{J}=0, \mathrm{D}=0)$. Compared with traditional droop control, VSG control has advantages, such as virtual damping and inertia. Ref. [12] proposed using a VSG control strategy in microgrids, which improves the closed-loop system dynamic response without changing 
the frequency accuracy compared to traditional droop methods. In [13,14], VSG provides virtual damping and inertia to realize the dynamic frequency regulation during the short period in a microgrid, respectively. These studies take advantage of a VSG to enhance the stability and reliability of a microgrid; in [15], a simplified VSG virtual inertia controller is introduced by Zhang B. It analyzes the impact of main control parameters on system stability and dynamic response. In addition, data-driven and reinforcement learning methods are gradually applied to the control field. Ref. [16] proposed a data-driven virtual synchronous generator (VSG) optimization control strategy, enabling DGs to adjust their control variables, according to current observations in a model-free manner, control system frequency and power dynamics. Although numerous studies on using a VSG control strategy for renewable energy have been conducted, they rarely consider the power quality problems caused by the imbalance mixed non-linear loads for the microgrid.

Compared with the traditional grid, there are more deterioration risks of power quality in energy production and transformation stages in the microgrid. On the power supply side, some renewable energy resources, such as solar and wind energy, have prominent fluctuation, randomness, and intermittent characteristics. It will cause fluctuations in the frequency and voltage of the microgrid, further reducing the power quality of the microgrid. When the microgrid operates in the island mode, it is also necessary to design a decentralized control strategy to ensure stable operation [17,18]. Ref. [19] proposed a novel controller for inverters to improve the frequency response of the microgrid under disturbances involving large frequency deviations, combining the advantages of droop control and master-slave control. Ref. [20] proposed a novel decentralized and communication-less controlled strategy for frequency and voltage regulation of the PV-Storage island microgrid. Ref. [21] proposed a closed-loop control law for linearization and control. The model is used to adjust the power through the model to change the grid voltage and frequency, thereby improving the quality of the system. On the load side, the increase in the imbalanced mixed non-linear load has a serious impact on the imbalance and the harmonic content of the outlet voltage of the microgrid inverter [22-24]. Additionally, DGs inverters carrying three-phase imbalance mixed non-linear loads create a significant amount of harmonics, especially the 5th and 7th. These can significantly degrade the voltage quality in the microgrid as well as the associated greater grid, which affects customers, demanding high power quality [25]. A unified power quality conditioner (UPQC) can be installed to limit harmonic distortion and improve the voltage and frequency of the macro-grid [26], but it is a kind of a costly solution. To autonomously mitigate harmonic voltage, harmonic compensation and imbalance control function can be embedded in the control system of the inverter. In [27,28], the droop characteristics of reactive harmonic power to the conductance are taken into consideration of the droop control. Therefore, grid harmonics can be suppressed by voltage controllers by subtracting the voltage and conductance harmonic current from the PI controller's current reference. A control strategy for voltage imbalance and harmonic suppression was proposed in [29] by realizing virtual impedance using resistive and inductive composites based on TOGI and SOGI. The overall system output impedance is controlled via PI control and the parallel connection of multiple proportion integral resonance (PIR) voltage controller to reduce the voltage imbalance and harmonics. Nevertheless, we did not verify the stability of this control strategy. Additionally, for power allocation issues of an imbalanced mixed non-linear load, harmonic and imbalance droop controllers were designed in [30] to share the harmonic power and the imbalance power among distributed generation units and improve the voltage quality at the point of common coupling. A novel fuzzy integral sliding mode current control strategy was proposed in [31], which can eliminate harmonics to the maximum, but the limitation is the method applied to the generator side for a direct-driven wind energy system. Ref. [32] proposed a comprehensive control strategy for voltage imbalance and harmonic suppression of multiple inverters based on droop control. It can effectively improve the power quality, but the inertia of the microgrid is not considered. 
According to the shortcomings of existing research, a comprehensive VSG control strategy for the harmonics and imbalanced voltage suppression of the multi-inverter parallel microgrid strategy is applied to solve the power quality problems caused by imbalanced mixed non-linear loads in the microgrid. The main contributions of this paper are as follows:

(1) Propose a harmonic and voltage imbalance suppression comprehensive strategy for distributed control of a multi-inverter parallel microgrid. This comprehensive strategy has an inertia section, which improves the lack of inertia in the traditional control method. Apart from improving the power quality of the microgrid, the secondary adjustment of the frequency is realized by the distributed control strategy.

(2) A small-signal state-space-based model is introduced for certain harmonics suppression to analyze non-linear load-induced system output characteristics caused by the superposition of fundamental and high-order harmonic components.

(3) To verify the validity of the proposed method, an accuracy model by the RTLAB semi-physical simulation system, the microgrid simulation is conducted.

\section{A Hierarchical VSG Secondary Control Strategy Based on Harmonic and Imbalance Principle}

As suggested from the basic control principle for VSG [33], the mathematical model of VSG is as follows [34]:

$$
\left\{\begin{array}{l}
J \frac{d \omega}{d t}=T_{s e t}+D_{p}\left(\omega_{n}-\omega\right)-T_{e} \\
T_{s e t}=\frac{P_{s e t}}{\omega_{n}} ; T_{e}=\frac{P_{e}}{\omega_{n}} \\
Q_{s e t}+\sqrt{2} D_{q}\left(U_{n}-U_{0}\right)-Q_{e}=\sqrt{2} K \frac{d E}{d t}
\end{array}\right.
$$

In (1), $P_{\text {set }}$ and $Q_{\text {set }}$ are the active and reactive power setpoint, respectively; $P_{e}$ and $Q_{e}$ are the actual active and reactive powers; $T_{\text {set }}$ is the torque setpoint; $T e$ is the electrical torque; $U_{0}$ is the effective output voltage; $U_{n}$ is the effective rated voltage; $J$ is the rotational moment of inertia; $K$ is the excitation coefficient; $D_{p}$ is the active droop coefficient; $D_{q}$ is the reactive droop coefficient; $\omega$ is the VSG angular frequency; and $\omega_{\mathrm{n}}$ is the rated angular frequency.

Figure 1 shows the control loop for VSG.

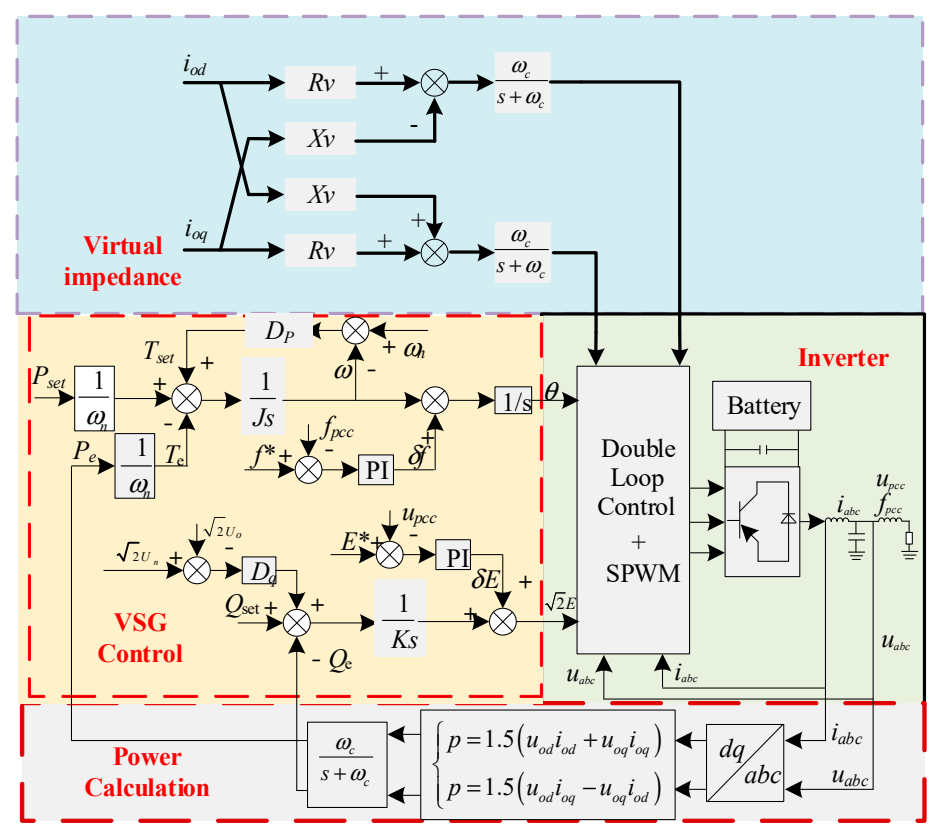

Figure 1. Virtual synchronous generator control loops. 


\subsection{The Strategy and Modelling Based on Harmonic Imbalance Principle}

Based on the instantaneous reactive power theory, voltage harmonics can be expressed, using the superposition of the DC component and $\mathrm{AC}$ components of various frequencies under the polar coordinate system, while three-phase imbalance can be presented as a non-zero negative sequence [22,35]. The microgrid power quality can be improved by controlling harmonic imbalance at various microgrid PCC nodes [36]. For example, the 5th harmonic can be expressed as

$$
\left\{\begin{array}{l}
u_{a 5}=U_{5} \sin 5 \omega t \\
u_{b 5}=U_{5} \sin \left(5 \omega t-5 \times \frac{2 \pi}{3}\right)=U_{5} \sin \left(5 \omega t+5 \times \frac{2 \pi}{3}\right) \\
u_{c 5}=U_{5} \sin \left(5 \omega t+5 \times \frac{2 \pi}{3}\right)=U_{5} \sin \left(5 \omega t-5 \times \frac{2 \pi}{3}\right)
\end{array}\right.
$$

The 5th harmonic component is in a negative sequence compared to the fundamental component. By applying negative sequence transformation in (2), we have

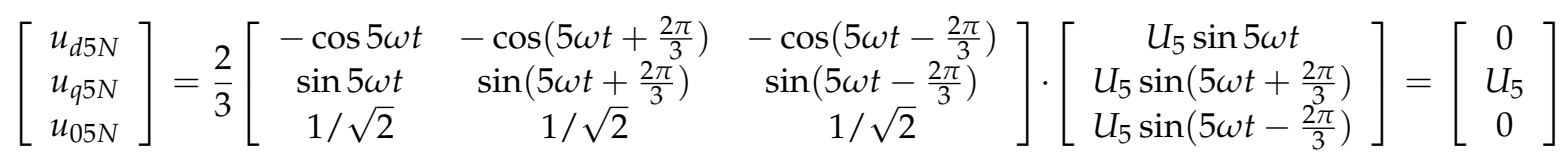

As suggested in (3), the 5 th harmonic component can be suppressed when $U_{5}$ is 0 .

Other high-order harmonics can also be suppressed using the same method.

Under imbalance voltage, the negative sequence voltage can be determined by

$$
\left[\begin{array}{l}
u_{d 1 N} \\
u_{q 1 N} \\
u_{01 N}
\end{array}\right]=\frac{2}{3}\left[\begin{array}{ccc}
\cos \omega t & \cos \left(\omega t+\frac{2 \pi}{3}\right) & \cos \left(\omega t-\frac{2 \pi}{3}\right) \\
-\sin \omega t & -\sin \left(\omega t+\frac{2 \pi}{3}\right) & -\sin \left(\omega t-\frac{2 \pi}{3}\right) \\
1 / \sqrt{2} & 1 / \sqrt{2} & 1 / \sqrt{2}
\end{array}\right] \cdot\left[\begin{array}{c}
U_{1} \sin \omega t \\
U_{1} \sin \left(\omega t-\frac{2 \pi}{3}\right) \\
U_{1} \sin \left(\omega t+\frac{2 \pi}{3}\right)
\end{array}\right]=\left[\begin{array}{c}
-U_{1} \sin 2 \omega t \\
U_{1} \cos 2 \omega t \\
0
\end{array}\right]
$$

Equation (4) shows that the negative sequence voltage is two times the fundamental sequence. As long as the negative sequence is zero, voltage imbalance can be suppressed.

System harmonic voltage loop control uses a standard PI controller. Therefore, its modeling process is similar to the voltage loop in traditional inverter control. For example, the 5th harmonic can be expressed using $\phi_{5 d}$ and $\phi_{5 q}$, which are:

$$
\left\{\begin{array}{l}
\frac{\mathrm{d} \phi_{5 d}}{\mathrm{~d} t}=u_{5 \circ d}^{*}-u_{5 o d} \\
\frac{\mathrm{d} \phi_{5 q}}{\mathrm{~d} t}=u_{5 \circ q}^{*}-u_{5 o q}
\end{array}\right.
$$

the 5th harmonic voltage control loop is

$$
\left\{\begin{array}{l}
i_{5 l d}^{*}=i_{5 o d}-\omega_{n} C_{f} v_{5 o q}+K_{5 p u}\left(u_{5 o d}^{*}-u_{5 o d}\right)+K_{5 i u} \phi_{5 d} \\
i_{5 l q}^{*}=i_{5 o q}-\omega_{n} C_{f} v_{5 o d}+K_{5 p u}\left(u_{5 o q}^{*}-u_{5 o q}\right)+K_{5 i u} \phi_{5 q}
\end{array}\right.
$$

the above equation can be linearized as

$$
\begin{aligned}
& {\left[\dot{\phi}_{5 d q}\right]=[0]\left[\Delta \phi_{5 d q}\right]+B_{5 u 1}\left[\Delta u_{5 o d q}^{*}\right]+B_{5 u 2}\left[\begin{array}{c}
\Delta i_{5 l d q} \\
\Delta u_{5 o d q} \\
\Delta i_{5 o d q}
\end{array}\right]} \\
& {\left[\Delta i_{5 l d q}^{*}\right]=C_{5 u}\left[\Delta \phi_{5 d q}\right]+D_{5 u 1}\left[\Delta u_{5 o d q}^{*}\right]+D_{5 u 2}\left[\begin{array}{c}
\Delta i_{5 l d q} \\
\Delta u_{5 o d q} \\
\Delta i_{5 o d q}
\end{array}\right]}
\end{aligned}
$$


where

$$
\begin{aligned}
& B_{5 u 1}=\left[\begin{array}{ll}
1 & 0 \\
0 & 1
\end{array}\right], B_{5 u 2}=\left[\begin{array}{cccccc}
0 & 0 & -1 & 0 & 0 & 0 \\
0 & 0 & 0 & -1 & 0 & 0
\end{array}\right] \\
& C_{5 u}=\left[\begin{array}{cc}
K_{5 i u} & 0 \\
0 & K_{5 i u}
\end{array}\right], D_{5 u 1}=\left[\begin{array}{cc}
K_{5 p u} & 0 \\
0 & K_{5 p u}
\end{array}\right] \\
& D_{5 u 2}=\left[\begin{array}{cccccc}
0 & 0 & -K_{5 p u} & -\omega_{n} C_{f} & 1 & 0 \\
0 & 0 & \omega_{n} C_{f} & -K_{5 p u} & 0 & 1
\end{array}\right]
\end{aligned}
$$

In the above equation, $K_{5 p u}$ is the scale factor for the voltage loop PI controller, and $K_{5 i u}$ is integral coefficient of the voltage loop PI controller.

\subsection{The Secondary Control Strategy and Modelling}

The output frequency $f_{p c c}$ and output voltage $E_{p c c}$ are collected at the microgrid before transmitting to local controllers via communication lines. Then, the frequency and output voltage are each subtracted by a frequency reference value $\mathrm{f}^{*}$ and an output voltage reference value $E^{*}$, before passing through the PI regulator, which generates the command signal added to the secondary control signal to control the inverter.

$$
\left\{\begin{array}{l}
\delta f_{i}=\left(k_{p F}+\frac{k_{i F}}{s}\right)\left(f^{*}-f_{p c c}\right) \\
\delta E_{i}=\left(k_{p E}+\frac{k_{i E}}{s}\right)\left(E^{*}-E_{p c c}\right)
\end{array}\right.
$$

Figure 2 shows the block diagram of secondary control block.

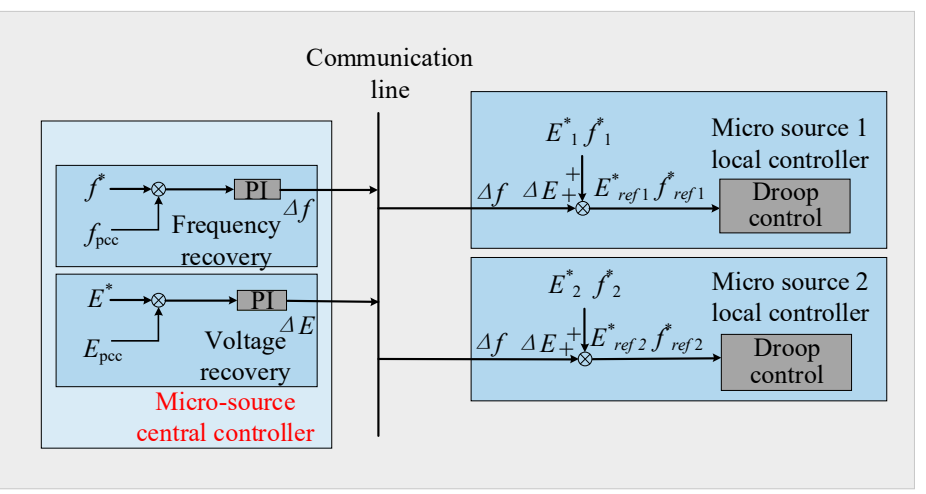

Figure 2. The block diagram of secondary control strategy.

The secondary frequency control applies PI control, taking the intermediate variable $S_{f}$ as

$$
\frac{\mathrm{d} S_{f}}{\mathrm{~d} t}=f^{*}-f_{p c c}
$$

The frequency control loop can then be calculated as

$$
\delta f=K_{p f}\left(f^{*}-f_{p c c}\right)+K_{i f} S_{f}
$$

The above equation can then be linearized as

$$
\begin{aligned}
& {\left[\dot{S}_{f}\right]=[0]\left[\Delta S_{f}\right]+B_{f}\left[\Delta f_{p c c}\right]} \\
& {[\Delta \delta f]=C_{f}\left[\Delta S_{f}\right]+D_{f}\left[\Delta f_{p c c}\right]}
\end{aligned}
$$

where

$$
\begin{gathered}
B_{f}=[-1] \\
C_{f}=\left[K_{i f}\right], D_{f}=\left[-K_{p f}\right]
\end{gathered}
$$


In the above equation, $K_{p f}$ is the scale factor for the secondary frequency loop PI controller; $K_{i f}$ is the integral coefficient of the secondary frequency loop PI controller.

The secondary voltage control also uses a PI controller; the intermediate variable $S_{E}$ is

$$
\frac{\mathrm{d} S_{E}}{\mathrm{~d} t}=E^{*}-E_{p c c}
$$

Therefore, the voltage control loop is

$$
\delta E=K_{p E}\left(E^{*}-E_{p c c}\right)+K_{i E} S_{E}
$$

The above system can be linearized as

$$
\begin{aligned}
& {\left[\dot{S}_{E}\right]=[0]\left[\Delta S_{E}\right]+B_{E}\left[\Delta E_{p c c}\right]} \\
& {[\Delta \delta E]=C_{E}\left[\Delta S_{E}\right]+D_{E}\left[\Delta E_{p c c}\right]}
\end{aligned}
$$

where

$$
\begin{aligned}
& B_{E}=[-1] \\
& C_{E}=\left[K_{i E}\right], D_{E}=\left[-K_{p E}\right]
\end{aligned}
$$

In the above equation, $K_{P E}$ is the scale factor for the secondary voltage loop PI controller; $K_{i E}$ is the integral coefficient of the secondary voltage loop PI controller.

The imbalance suppression loop can be modeled in the same manner as the harmonic control loop. It also uses a standard PI controller and negative sequence voltage compensation suppressing negative sequence components, further eliminating the problem of three-phase voltage imbalance.

Figure 3 shows the system diagram of the hierarchical VSG secondary control strategy based on harmonic imbalance.

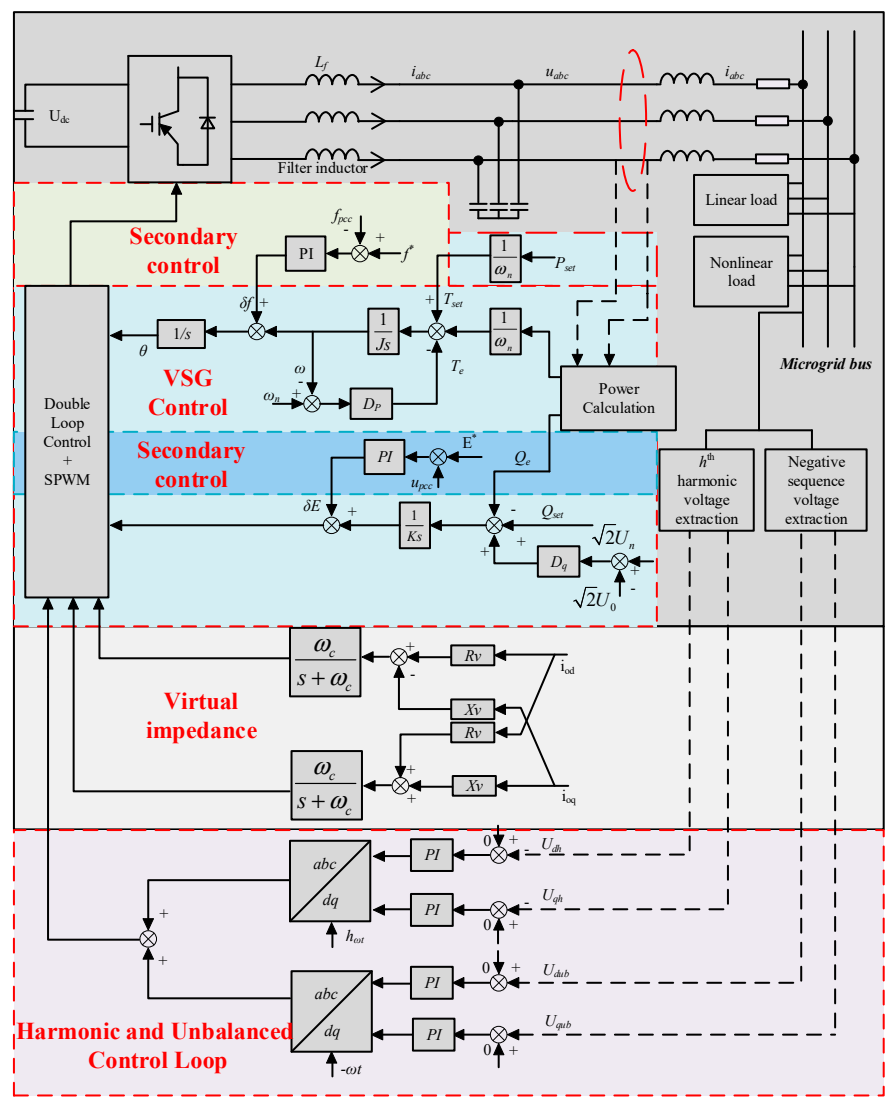

Figure 3. The block diagram of main control strategy. 
From Figure 3, we built the multi-inverter microgrid modeling based on VSG. The voltage and current information of the microgrid system is measured from the PCC point, and its active power and reactive power are calculated by the power calculation module. Then, the calculation amount of power and reactive power is sent to the voltage control loop and the frequency control loop, using the harmonic and voltage imbalance suppression strategy for distributed control of multiple parallel VSG. In turn, the power quality of the microgrid system is effectively improved and solves the problem of a lack of inertia in the microgrid system.

\section{Small-Signal Model for Parallel-Based VSG Control Operation of \\ Multi-Inverter Microgrid}

The small-signal model for parallel-based VSG control operation of multi-inverter microgrid is analyzed: VSG inverter mode, virtual impedance, double closed-loop control for voltage and current, and LC filter small-signal model [37,38]. The small-signal model can be expressed through state-space representation.

\subsection{Small-Signal Model for Parallel based VSG Control}

\subsubsection{VSG Power Loop Model Modeling}

The VSG power loop model can be expressed as

$$
\begin{aligned}
& {\left[\begin{array}{c}
\dot{\Delta \theta} \\
\Delta \omega \\
\Delta E
\end{array}\right]=A_{p}\left[\begin{array}{c}
\Delta \theta \\
\Delta \omega \\
\Delta E
\end{array}\right]+B_{p}\left[\begin{array}{c}
\Delta i_{l d q} \\
\Delta u_{o d q} \\
\Delta i_{o d q}
\end{array}\right]+B_{p \omega} \Delta \omega_{c o m}} \\
& {\left[\begin{array}{c}
\Delta \omega \\
\Delta u_{o n d q}
\end{array}\right]=\left[\begin{array}{c}
C_{p \omega} \\
C_{p u}
\end{array}\right]\left[\begin{array}{c}
\Delta \theta \\
\Delta \omega \\
\Delta E
\end{array}\right]}
\end{aligned}
$$

where

$$
\begin{aligned}
& A_{p}=\left[\begin{array}{ccc}
0 & 1 & 0 \\
0 & -\frac{D_{p}}{J} & 0 \\
0 & 0 & -\frac{D_{q}}{K}
\end{array}\right] ; B_{p \omega}=\left[\begin{array}{c}
-1 \\
0 \\
0
\end{array}\right] ; \\
& B_{p}=\left[\begin{array}{cccccc}
0 & 0 & 0 & 0 & 0 & 0 \\
0 & 0 & -\frac{I_{o d}}{J \omega_{n}} & -\frac{I_{o q}}{J \omega_{n}} & -\frac{U_{o d}}{J \omega_{n}} & -\frac{U_{o q}}{J \omega_{n}} \\
0 & 0 & \frac{I_{o q}}{K} & -\frac{I_{o d}}{K} & -\frac{U_{o q}}{K} & \frac{U_{o d}}{K}
\end{array}\right] \text {; } \\
& C_{p \omega}=\left[\begin{array}{ccc}
0 & 1 & 0
\end{array}\right] ; C_{p u}=\left[\begin{array}{ccc}
0 & 0 & \frac{\sqrt{2}}{2} \\
0 & 0 & 0
\end{array}\right]
\end{aligned}
$$

In the above equation, $i_{l d q}$ is the VSG induction current; $u_{o d q}$ is the VSG output voltage; and $i_{o d q}$ is the VSG output current. $\omega_{\text {com }}$ is the reference coordinate, $\omega$ is the frequency of the microgrid, and $\theta$ is the angle between micro sources and the common coordinate.

\subsubsection{Virtual Impedance Modelling}

Line impedance can cause a phase shift, and parallel connections of multi-inverters may encounter power balance issues. To solve these issues, a virtual impedance-based control strategy is used to guarantee inductive droop in the system lines. The S-domain control is expressed as follows:

$$
\left\{\begin{array}{l}
u_{o d}{ }^{*}=u_{o n d}+\frac{\omega_{c}}{s+\omega_{c}}\left(i_{o d} \cdot R_{v}-i_{o q} \cdot X_{v}\right) \\
u_{o q}{ }^{*}=u_{o n q}+\frac{\omega_{c}}{s+\omega_{c}}\left(i_{o d} \cdot X_{v}+i_{o q} \cdot R_{v}\right)
\end{array}\right.
$$

where $u_{o d}{ }^{*}$ and $u_{o q}{ }^{*}$ are the voltage output of the virtual impedance; $u_{o n d}$ and $u_{o n q}$ are the input voltage of the virtual impedance; and $\omega_{c}$ is the first level inertial stopping frequency. 
$i_{o d}$, and $i_{o}$ are the system output current; $X_{v}$ and $R_{v}$ are the virtual reactance and virtual resistance.

Linearize (17), rearranging the equation for $X_{d}, X_{q}$ :

$$
\left\{\begin{array}{l}
X_{d}=u_{o d}{ }^{*}-u_{o n d} \\
X_{q}=u_{o q}{ }^{*}-u_{o n q}
\end{array}\right.
$$

By linearizing and simplifying (18) and (19), the small-signal model state space for virtual impedance can be expressed as

$$
\begin{aligned}
& {\left[\begin{array}{l}
\Delta X_{d} \\
\Delta X_{q}
\end{array}\right]=A_{v}\left[\begin{array}{l}
\Delta X_{d} \\
\Delta X_{q}
\end{array}\right]+B_{v}\left[\begin{array}{l}
\Delta i_{o d} \\
\Delta i_{o q}
\end{array}\right]} \\
& {\left[\begin{array}{l}
\Delta u_{o d}^{*} \\
\Delta u_{o q}^{*}
\end{array}\right]=C_{v}\left[\begin{array}{l}
\Delta X_{d} \\
\Delta X_{q}
\end{array}\right]+D_{v}\left[\begin{array}{l}
\Delta i_{o d} \\
\Delta i_{o q}
\end{array}\right]}
\end{aligned}
$$

where

$$
\begin{array}{lll}
A_{v}=\left[\begin{array}{cc}
-\omega_{c} & 0 \\
0 & -\omega_{c}
\end{array}\right] ; & B_{v}=\left[\begin{array}{cc}
\omega_{c} R_{v} & -\omega_{c} X_{v} \\
\omega_{c} X_{v} & \omega_{c} R_{v}
\end{array}\right] ; \\
C_{v}=\left[\begin{array}{ll}
1 & 0 \\
0 & 1
\end{array}\right] ; & D_{v}=\left[\begin{array}{ll}
1 & 0 \\
0 & 1
\end{array}\right]
\end{array}
$$

As shown in (18), the impact of $X_{v}$ and $R_{v}$ to the system virtual impedance can be determined and further used to observe and analyze power distribution in the microgrid.

\subsubsection{Voltage and Current Loops Modeling}

The system voltage control loop uses the standard PI controller. Taking the variables $\phi_{d}$ and $\phi_{q}$, linearized, the voltage loop small-signal can be calculated as

$$
\begin{aligned}
& {\left[\dot{\phi}_{d q}\right]=[0]\left[\Delta \phi_{d q}\right]+B_{u 1}\left[\Delta u_{o d q}^{*}\right]+B_{u 2}\left[\begin{array}{c}
\Delta i_{l d q} \\
\Delta u_{o d q} \\
\Delta i_{o d q}
\end{array}\right]} \\
& \left.\left[\Delta i_{l d q}^{*}\right]=C_{u}[\Delta] \phi_{d q}\right]+D_{u 1}\left[\Delta u_{o d q}^{*}\right]+D_{u 2}\left[\begin{array}{c}
\Delta i_{l d q} \\
\Delta u_{o d q} \\
\Delta i_{o d q}
\end{array}\right]
\end{aligned}
$$

where

$$
\begin{aligned}
& B_{u 1}=\left[\begin{array}{ll}
1 & 0 \\
0 & 1
\end{array}\right], B_{u 2}=\left[\begin{array}{cccccc}
0 & 0 & -1 & 0 & 0 & 0 \\
0 & 0 & 0 & -1 & 0 & 0
\end{array}\right] \\
& C_{u}=\left[\begin{array}{cc}
K_{i u} & 0 \\
0 & K_{i u}
\end{array}\right], D_{u 1}=\left[\begin{array}{cc}
K_{p u} & 0 \\
0 & K_{p u}
\end{array}\right] \\
& D_{u 2}=\left[\begin{array}{cccccc}
0 & 0 & -K_{p u} & -\omega_{n} C_{f} & 1 & 0 \\
0 & 0 & \omega_{n} C_{f} & -K_{p u} & 0 & 1
\end{array}\right]
\end{aligned}
$$

By linearizing the above equation, the current loop small signal can be expressed as

$$
\begin{aligned}
& {\left[\dot{\gamma}_{d q}\right]=[0]\left[\Delta \gamma_{d q}\right]+B_{c 1}\left[\Delta i_{l d q}^{*}\right]+B_{c 2}\left[\begin{array}{c}
\Delta i_{l d q} \\
\Delta u_{o d q} \\
\Delta i_{o d q}
\end{array}\right]} \\
& {\left[\Delta u_{i d q}^{*}\right]=C_{c}\left[\Delta \gamma_{d q}\right]+D_{c 1}\left[\Delta i_{l d q}^{*}\right]+D_{c 2}\left[\begin{array}{c}
\Delta i_{l d q} \\
\Delta u_{o d q} \\
\Delta i_{o d q}
\end{array}\right]}
\end{aligned}
$$


where

$$
\begin{aligned}
& B_{c 1}=\left[\begin{array}{ll}
1 & 0 \\
0 & 1
\end{array}\right], \quad B_{c 2}=\left[\begin{array}{cccccc}
-1 & 0 & 0 & 0 & 0 & 0 \\
0 & -1 & 0 & 0 & 0 & 0
\end{array}\right] \\
& C_{c}=\left[\begin{array}{cc}
K_{i c} & 0 \\
0 & K_{i c}
\end{array}\right], \quad D_{c 1}=\left[\begin{array}{cc}
K_{p c} & 0 \\
0 & K_{p c}
\end{array}\right] \\
& D_{c 2}=\left[\begin{array}{cccccc}
-K_{p c} & -\omega_{n} L_{f} & 0 & 0 & 0 & 0 \\
\omega_{n} L_{f} & -K_{p c} & 0 & 0 & 0 & 0
\end{array}\right]
\end{aligned}
$$

where $K_{p u}$ and $K_{i u}$ are the voltage loop PI controller P gain and I gain; $K_{p c}$ and $K_{i c}$ are the current loop PI controller P gain and I gain; $C_{f}$ is the filter capacitance; and $L_{f}$ is the filter inductance.

\subsubsection{LC Filter Modeling}

In the steady state, the current loop output voltage $u_{i d q}^{*}$ is $u_{i d q}$. Based on the filter coupling characteristics, the small-signal model can be expressed as

$$
\left[\begin{array}{c}
\dot{i}_{l d q} \\
\Delta u_{o d q} \\
\Delta i_{o d q}
\end{array}\right]=A_{L C}\left[\begin{array}{c}
\Delta i_{l d q} \\
\Delta u_{o d q} \\
\Delta i_{o d q}
\end{array}\right]+B_{L C 1}\left[\Delta u_{b d q}\right]++B_{L C 2}\left[\Delta u_{i d q}\right]+B_{L C 3}[\Delta \omega]
$$

where

$$
A_{L C}=\left[\begin{array}{cccccc}
-\frac{r L_{f}}{L_{f}} & \omega_{0} & -\frac{1}{L_{f}} & 0 & 0 & 0 \\
-\omega_{0} & -\frac{r L_{f}}{L_{f}} & 0 & -\frac{1}{L_{f}} & 0 & 0 \\
\frac{1}{C_{f}} & 0 & 0 & \omega_{0} & -\frac{1}{C_{f}} & 0 \\
0 & \frac{1}{C_{f}} & -\omega_{0} & 0 & 0 & -\frac{1}{C_{f}} \\
0 & 0 & \frac{1}{L_{c}} & 0 & -\frac{r L_{c}}{L_{c}} & \omega_{0} \\
0 & 0 & 0 & \frac{1}{L_{c}} & -\omega_{0} & -\frac{r L_{c}}{L_{c}}
\end{array}\right] B_{L C 1}=\left[\begin{array}{cc}
\frac{1}{L_{f}} & 0 \\
0 & \frac{1}{L_{f}} \\
0 & 0 \\
0 & 0 \\
0 & 0 \\
0 & 0
\end{array}\right], B_{L C 2}=\left[\begin{array}{ccc}
0 & 0 \\
0 & 0 \\
0 & 0 \\
0 & 0 \\
-\frac{1}{L_{c}} & 0 \\
0 & -\frac{1}{L_{c}}
\end{array}\right]
$$

In the above equation, $L_{c}$ and $r_{c}$ are the system inductance and resistance; $r_{f}$ is the filter parasitic resistance; and $u_{i d q}$ is the PCC point $d, q$ axes voltage.

\subsubsection{Small-Signal Model for VSG Inverter}

The small-signal model for the VSG inverter can be produced by combining models described in the previous sections. The inverter model can be transformed into a uniform coordinate system for better representation. As shown in Figure 4,

$$
\theta=\int\left(\omega_{j}-\omega_{i}\right)
$$

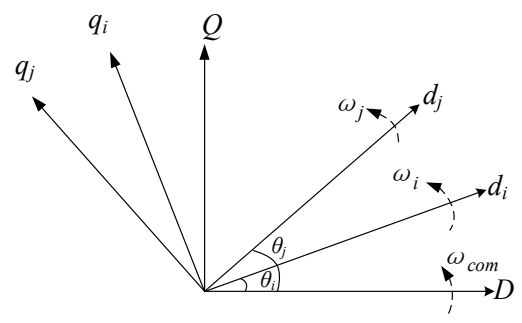

Figure 4. Transformation of the uniform coordinate system.

The reference coordinates $D-Q$ rotate with an angular speed of $\omega_{\text {com }}$. The $d_{i}-q_{i}$ coordinate system and $d_{j}-q_{j}$ coordinate system represents the coordinate of inverter $i, j$, which rotates with the angular speed of $\omega_{i}$ and $\omega_{j} . \theta_{i}$ and $\theta_{j}$ represent the angular difference between the rotational coordinate of VSG $i, j$ and the uniform rotational coordinate. 
By applying the above coordinate transformation, individual inverter input variable $u_{i d q}$ and output variable $i_{\text {odq }}$ can be transformed into the uniform reference coordinate system.

$$
\begin{gathered}
T_{s}=\left[\begin{array}{cc}
\cos \theta & -\sin \theta \\
\sin \theta & \cos \theta
\end{array}\right] \\
T_{u}=\left[\begin{array}{ccc}
-u_{i d} \sin \theta+u_{i q} \cos \theta & 0 & 0 \\
-u_{i d} \cos \theta-u_{i q} \sin \theta & 0 & 0
\end{array}\right] \\
T_{i}=\left[\begin{array}{c}
-i_{o d} \sin \theta-i_{o q} \cos \theta \\
i_{o d} \cos \theta-i_{o q} \sin \theta
\end{array}\right]
\end{gathered}
$$

The complete VSG inverter model can be represented as

$$
\begin{aligned}
& {\left[\Delta \dot{x}_{i n v i}\right]=A_{i n v i}\left[\Delta x_{i n v i}\right]+B_{i n v i}\left[\Delta u_{i d q}\right]+B_{i \omega}\left[\Delta \omega_{c o m}\right]} \\
& {\left[\begin{array}{c}
\Delta \omega_{i} \\
\Delta i_{\text {oidq }}
\end{array}\right]=\left[\begin{array}{c}
C_{i n v \omega i} \\
C_{i n v c i}
\end{array}\right]\left[\Delta x_{i n v i}\right]}
\end{aligned}
$$

where

$$
\begin{aligned}
A_{i n v} & =\left[\begin{array}{cc}
A_{i n v 1}+B_{1 \omega} C_{i n v \omega 1} & 0 \\
0 & A_{i n v 2}+B_{2 \omega} C_{i n v \omega 1}
\end{array}\right] \\
B_{i n v} & =\left[\begin{array}{c}
B_{i n v 1} \\
B_{i n v 2}
\end{array}\right] ; C_{i n v c}=\left[\begin{array}{cc}
C_{i n v c 1} & 0 \\
0 & C_{i n v c 2}
\end{array}\right] ; C_{i n v \omega}=\left[\begin{array}{ll}
C_{i n v \omega 1} & C_{i n v \omega 2}
\end{array}\right]
\end{aligned}
$$

In the above equation, $\Delta x_{i n v}$ is the inverter state variable of the VSG; $u_{i d q}$ is the system PCC nodal voltage; $\omega_{i}$ is the angular frequency of $i$-th VSG; $i_{\text {odq } i}$ is the output current of $i$-th VSG. $A_{i n v}$ is the inverter state matrix of the VSG; $\Delta u_{i d q}$ is the inverter output voltage of the VSG; $B_{i n v}$ and $B_{i \omega}$ are the inverter input matrices of the VSG; and $C_{i n v c}$ is the inverter output matrix of the VSG.

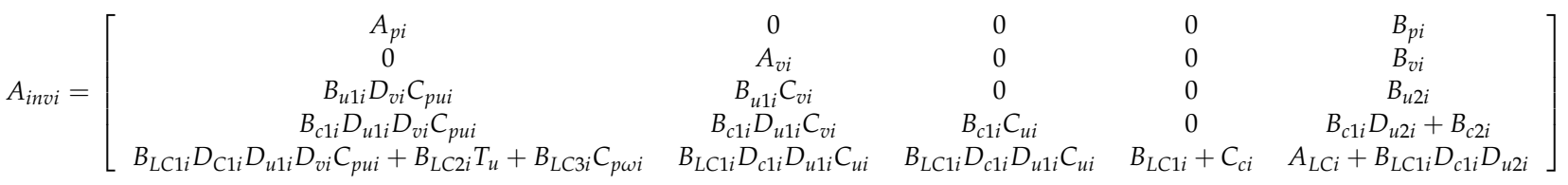

$$
\begin{aligned}
& B_{\text {invi }}=\left[\begin{array}{llll}
0 & 0 & 0 & B_{L C 2 i} T_{s}^{-1}
\end{array}\right]_{15 \times 2}^{T} \quad C_{i n v \omega i}=\left\{\begin{array}{ccc}
{\left[\begin{array}{cccc}
C_{p \omega} & 0 & 0 & 0
\end{array}\right]_{1 \times 15}} & i=1 \\
{\left[\begin{array}{cccc}
0 & 0 & 0 & 0
\end{array}\right]_{1 \times 15}} & i \neq 1
\end{array}\right.
\end{aligned}
$$

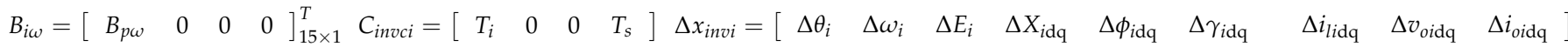

\subsection{The Root Locus of the Parallel Based VSG Control}

Figures 5-8 show the stability analysis of harmonic imbalance suppression for the multi-inverter parallel VSG operation under different sets of parameters.

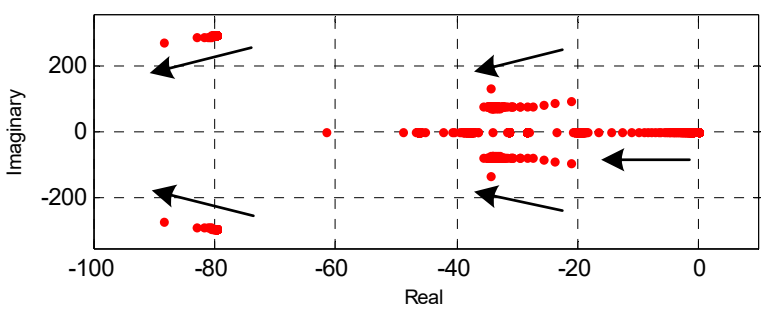

(a)

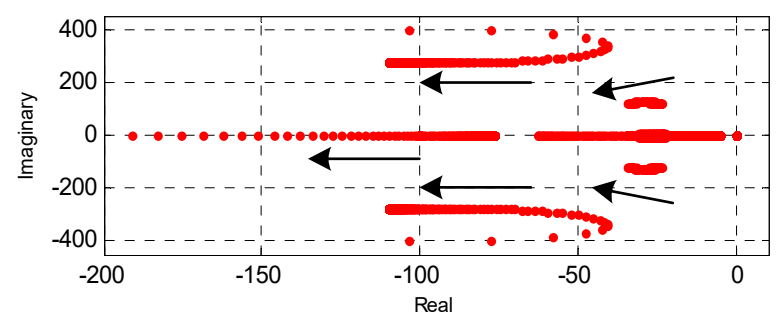

(b)

Figure 5. The system root locus diagram for the changes of $J$ and $K$. (a) The root locus of the inertia coefficient $J$ of the VSG changes from 0.04 to 10 ; (b) the root locus of the excitation coefficient $K$ of the VSG changes from 0.001 to 100 . 


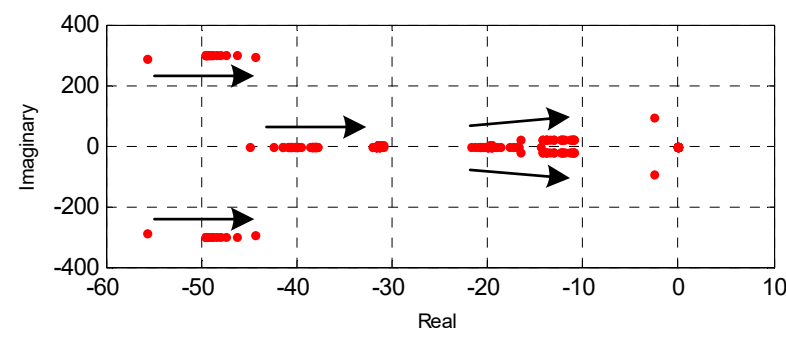

(a)

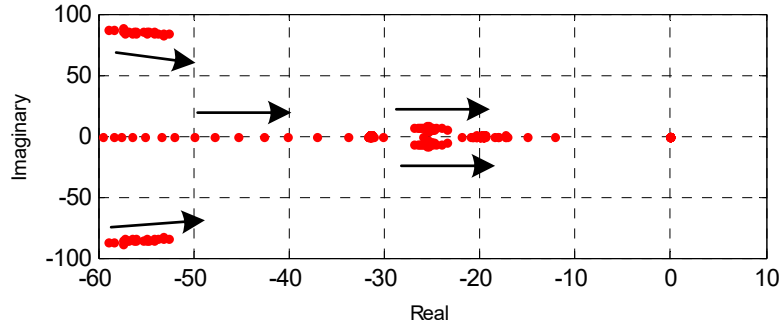

(b)

Figure 6. The system root locus diagram for the changes of $D_{p}$ and $D_{q}$. (a) The root locus of the droop coefficient $D_{p}$ of the VSG changes from 0 to 500; (b) the root locus of the droop coefficient $D_{q}$ of the VSG changes from 0 to 1000 .

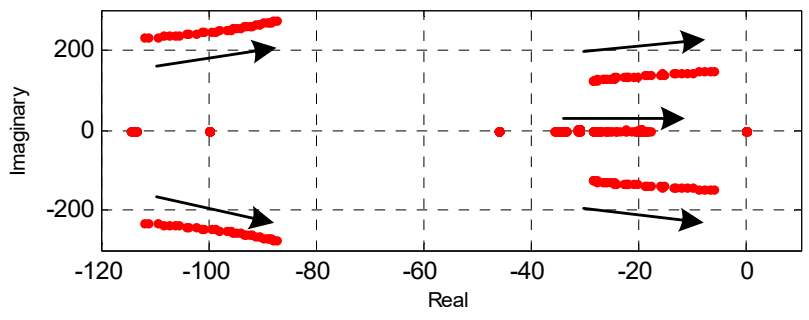

(a)

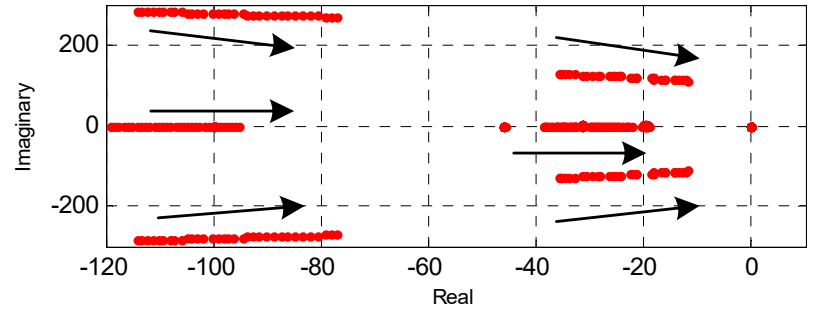

(b)

Figure 7. The system root locus diagram for the changes of $R_{v}$ and $X_{v}$. (a) The root locus of virtual resistance $R_{v}$ changes from 0 to 0.8 ; (b) the root locus of virtual reactance $X_{v}$ changes from 0 to 0.8 .

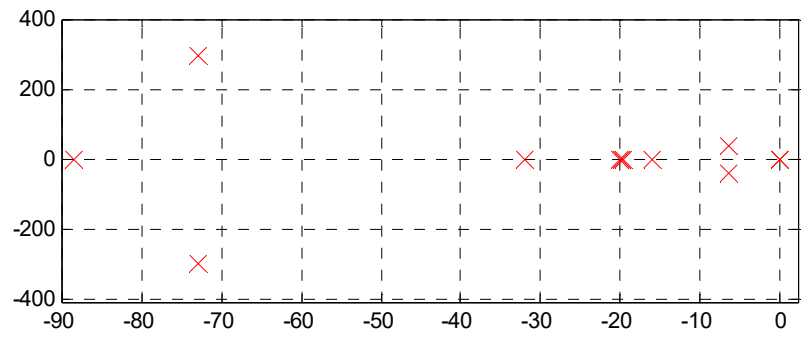

Figure 8. The root locus diagram of the parameters used in the experiment.

Figure $5 \mathrm{a}$ is the system root locus diagram when the inertia coefficient $J$ of the VSG changes from 0.04 to 10 , Figure $5 b$ is the system root locus diagram of the VSG excitation coefficient $K$ varying from 0.001 to 100 . As shown in Figure 5a, as $J$ increases, the overall trend of the root locus of the system shifts to the left, the dynamic characteristics gradually decrease, and the stability increases. When $J$ is larger, the system response speed is slower. As suggested in Figure $5 b$, as $K$ increases, the feature root shifts to the left, and the system stability gradually increases.

Figure $6 \mathrm{a}, \mathrm{b}$ shows the root trajectories of the system when the active droop coefficient $D_{p}$ changes from 0 to 500 and the reactive droop coefficient $D_{q}$ changes from 0 to 1000 .

Figure 6a suggests that as $D_{p}$ increases, the root locus of the system moves horizontally to the right, indicating that $D_{p}$ has an increasing influence on the stability of the system. However, it can be seen that it has little impact on the dynamic characteristics of the system. The system is unstable when $D_{p}$ is too large.

Figure $6 \mathrm{~b}$ suggests that as $D_{q}$ increases, the system root locus and $D_{q}$ trend are the same, which has little impact on the dynamic characteristics of the system and has great influence on the steady-state characteristic. When $D_{q}$ is too large, the system is unstable.

Figure 7a,b shows system root trajectories for the virtual resistance $R_{v}$ from 0 to 0.8 and the virtual reactance $X_{v}$ from 0 to 0.8 . As shown in Figure $7 \mathrm{a}$, as $X_{v}$ increases, the 
characteristic root of the system moves to the right, and the characteristic root gradually moves away from the real axis.

Figure $7 \mathrm{~b}$ indicates that the dynamic characteristics of the system are gradually enhanced, and the stability is decreased as $X_{v}$ increases.

Figure 8 shows the root locus points calculated based on the parameters used in the harmonic imbalance control experiment. It can be seen that all the characteristic roots of the system are located in the left half-plane, which can determine the stability of the harmonic imbalance control system while also verifying the small-signal model of this paper.

\section{Experiment Results}

The proposed method is tested using the RTLAB semi-physical simulation system as shown in Figure 9. This simulation platform comprises the RTLAB target computer OP5600, power supply, RTLAB host computer, and data acquisition system DEWE5000. The host computer communicates with RTLAB through TCP/IP, and the controller communicates with RTLAB through the data acquisition board OP5142.

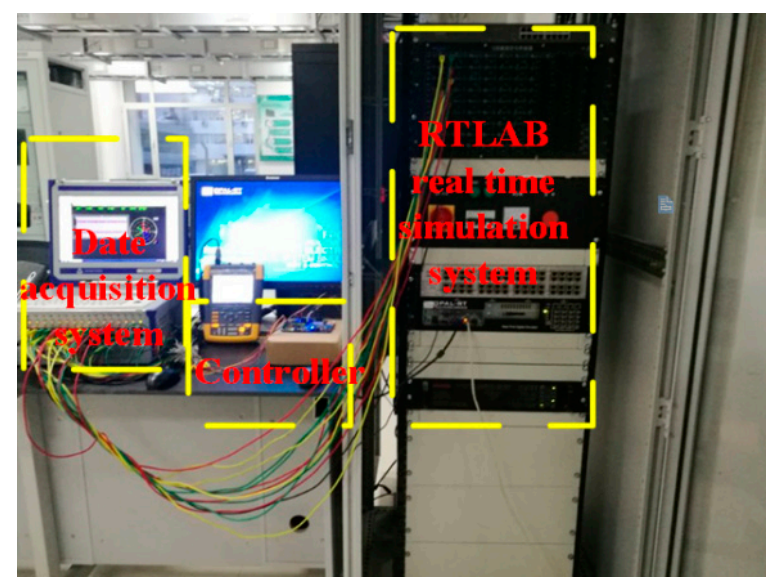

Figure 9. Experiments setup with RTLAB real-time simulation system.

The experiment uses two VSGs for parallel connection, with two fixed impedance loads and one imbalanced nonlinear load. Two VSGs both have a rated power of $P_{\text {ref }}=30 \mathrm{~kW}$, reactive power rating of $Q_{r e f}=0 \mathrm{kvar}$, linear load active power of $10 \mathrm{~kW}$, reactive power of $0 \mathrm{kvar}$, non-linear load active power of $20 \mathrm{~kW}$, and reactive power of $0 \mathrm{kvar}$.

The parameters in the experiment are shown in Table 1.

Table 1. Information of experimental parameters.

\begin{tabular}{|c|c|c|c|c|c|}
\hline System Parameters & Symbol & Numerical Value & System Parameters & Symbol & Numerical Value \\
\hline Filter inductor & $L_{f}$ & $0.6 \times 10^{-3} \mathrm{H}$ & VSG Inertia coefficient & $J$ & 0.2 \\
\hline Filter parasitic resistance & $R_{f}$ & $1 \times 10^{-2} \Omega$ & VSG excitation coefficient & $K$ & 7 \\
\hline Filter capacitor & $C_{f}$ & 0 & Active droop coefficient & $m_{p}$ & 15 \\
\hline DC bus voltage & $U_{d c}$ & $700 \mathrm{~V}$ & Reactive droop coefficient & $n_{q}$ & 2000 \\
\hline Line resistance & Lline & $2.8 \times 10^{-3} \mathrm{H}$ & Voltage loop control proportional coefficient & $K_{u p}$ & 10 \\
\hline Line inductance & $R_{\text {line }}$ & $4.28 \times 10^{-2} \Omega$ & Voltage loop control integral coefficient & $K_{u i}$ & 100 \\
\hline VSG1 Virtual resistance & $R_{v 1}$ & $0 \Omega$ & Current loop control proportional coefficient & $K_{i p}$ & 5 \\
\hline VSG2 Virtual resistance & $R_{v 2}$ & $0 \Omega$ & $\begin{array}{c}\text { Harmonic suppression loop proportional } \\
\text { coefficient }\end{array}$ & $K_{\text {hup }}$ & 10 \\
\hline VSG1 Virtual reactance & $L_{v 1}$ & $0.01 \mathrm{H}$ & Harmonic suppression loop integral coefficient & $K_{h u i}$ & 50 \\
\hline VSG2 Virtual reactance & $L_{v 2}$ & $0.01 \mathrm{H}$ & $\begin{array}{c}\text { imbalance suppression loop proportional } \\
\text { coefficient }\end{array}$ & $K_{\text {hup }}$ & 3 \\
\hline VSG Rated frequency & $f^{*}$ & $50 \mathrm{~Hz}$ & $\begin{array}{c}\text { imbalance suppression loop integral } \\
\text { coefficient }\end{array}$ & $K_{h u i}$ & 2 \\
\hline VSG Rated voltage & $E^{*}$ & $311 \mathrm{~V}$ & & & \\
\hline
\end{tabular}

The experimental results are shown in Figures 10-16. 


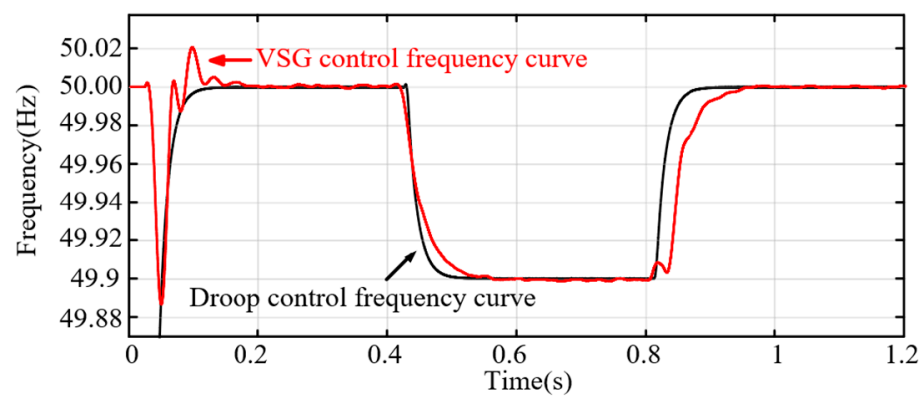

Figure 10. Experimental results for frequency waveform comparison of droop control and VSG control.

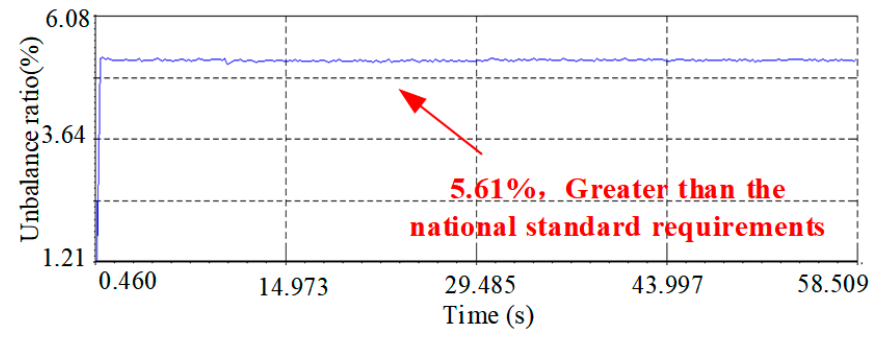

(a)

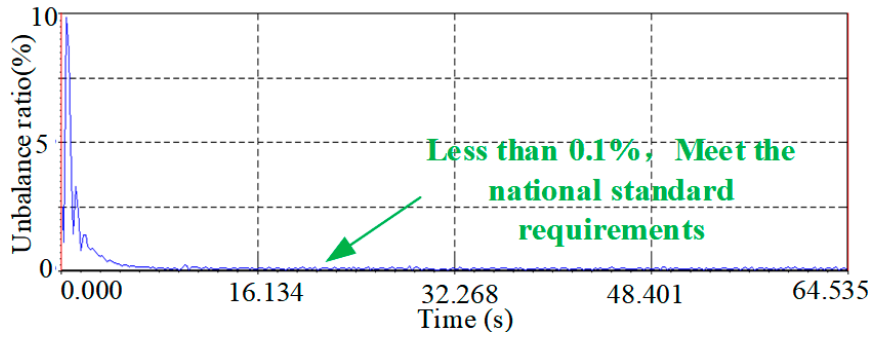

(b)

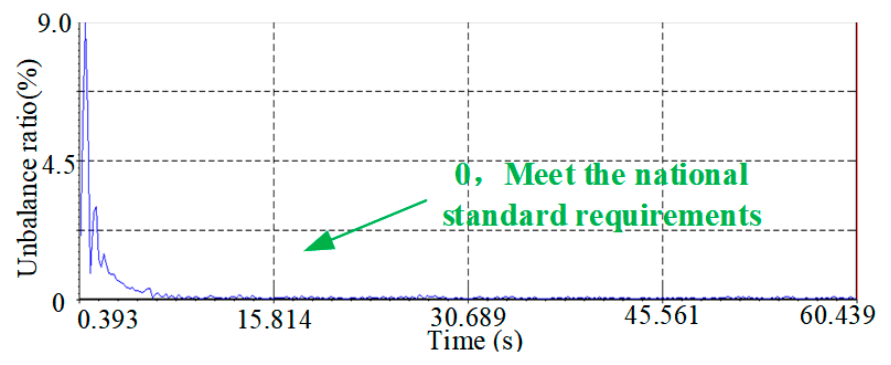

(c)

Figure 11. Experimental results for the waveform of imbalances ratio (a) with the traditional PI control strategy; (b) with the harmonic and imbalance voltage suppression of multi-inverter parallel VSG; (c) with the harmonic and imbalance voltage suppression of multi-inverter parallel VSG adding a secondary control strategy.

As shown in Figure 10, when the load is connected in $0.4 \mathrm{~s}$, the droop control strategy frequency curve decreases rapidly, while the frequency curve of the VSG control strategy decreases to the same frequency at about $0.6 \mathrm{~s}$ due to the existence of inertia. In addition, the frequency curve of the droop control strategy rises rapidly when the load is cut off in $0.8 \mathrm{~s}$, while the VSG control strategy returns to stability at 1s. It can be seen that compared with droop control, VSG control can alleviate the impact on the system during load switching.

As shown in Figure 11a, the imbalance ratio of the system that does not contain the harmonic imbalanced suppression loop reaches and remains at $5.61 \%$ soon after the experiment begins. It indicates that the system generates great voltage imbalances when the under imbalanced load and the voltage waveform is distorted. In Figure $11 \mathrm{~b}$, the imbalance ratio can be reduced from $5.61 \%$ to less than $0.1 \%$, which fully meets Chinese national standards by introducing an imbalanced suppression loop to the parallel system.

When the secondary control strategy is added in Figure 11c, the fluctuation of the voltage imbalance is not affected, and stability can still be achieved. The imbalance ratio is close to 0 , which indicates that the secondary control strategy does not affect the imbalance suppression loop. 
FFT

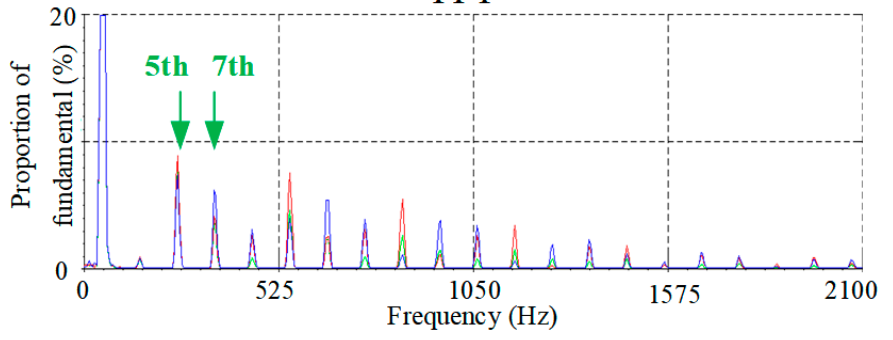

(a)

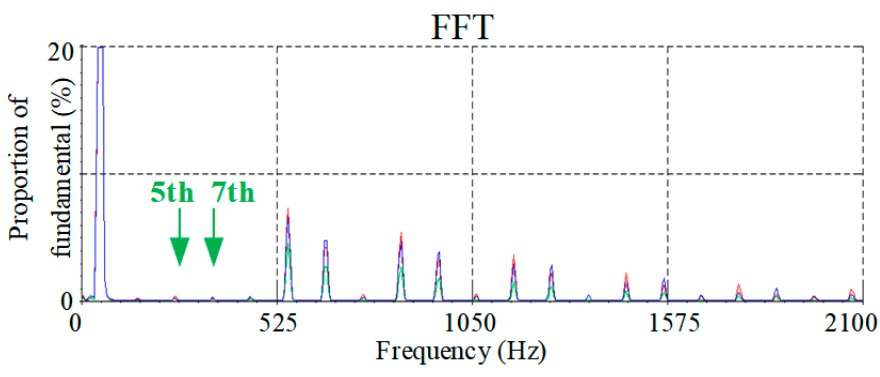

(b)

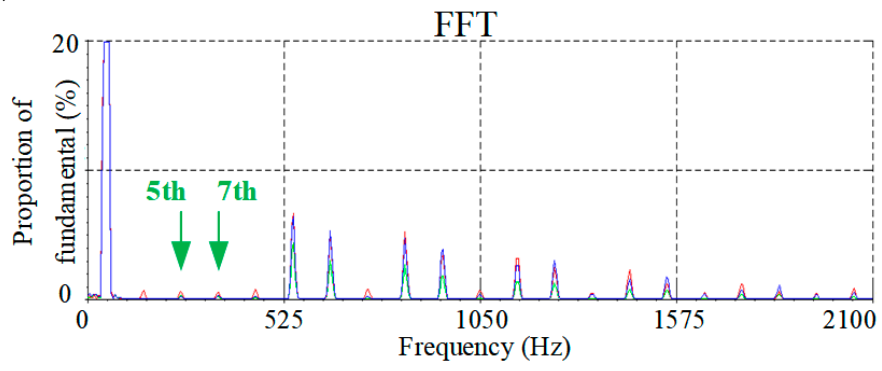

(c)

Figure 12. Experimental results for the FFT analysis harmonic waveform (a) with the traditional PI control strategy; (b) with the harmonic and imbalance voltage suppression of multi-inverter parallel VSG; (c) with the harmonic and imbalance voltage suppression of multi-inverter parallel VSG adding a secondary control strategy.

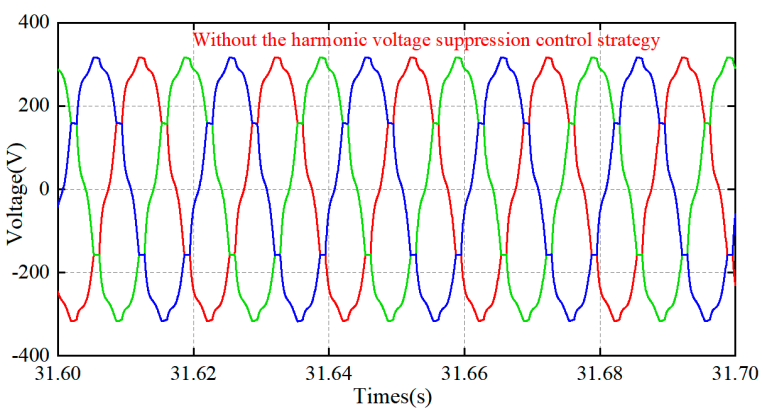

(a)

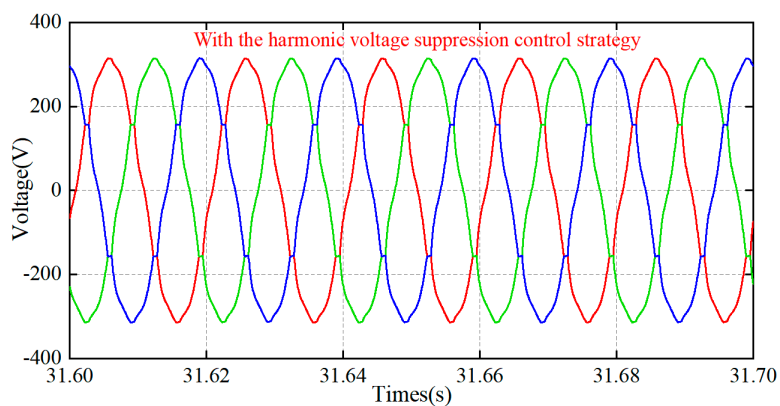

(b)

Figure 13. Experimental results for the voltage waveform of microgrid for PCC point (a) without the harmonic voltage suppression of multi-inverter parallel VSG adding a secondary control strategy; (b) with the harmonic voltage suppression of multi-inverter parallel VSG adding a secondary control strategy.

As shown in Figure 12a, for conventional parallel VSG systems, the system generates harmonics of different frequencies due to the nonlinear load. The 5th and 7th harmonics have the highest content, reducing the power quality of the microgrid, and the amplitude gradually decreases as the frequency increases.

After adding the 5th and 7th harmonic suppression loops, it can be seen that the corresponding amplitude is significantly reduced, and the harmonic control target can be achieved. After the secondary control strategy is added to Figure 12b, the harmonic amplitude does not change compared with Figure 12c.

As shown in Figure 13a, the experimental results for the voltage waveform of microgrid for PCC point are distorted. In Figure 13b, the voltage waveform is obviously improved after adding the harmonic voltage suppression of the multi-inverter parallel VSG control strategy, which indicates the effectiveness of the proposed harmonic suppression strategy. 


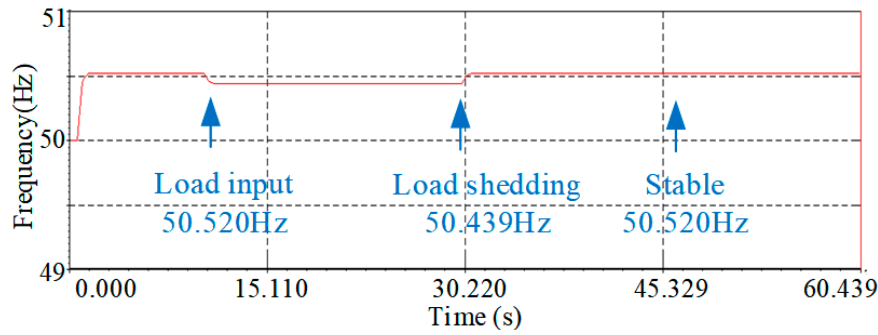

(a)

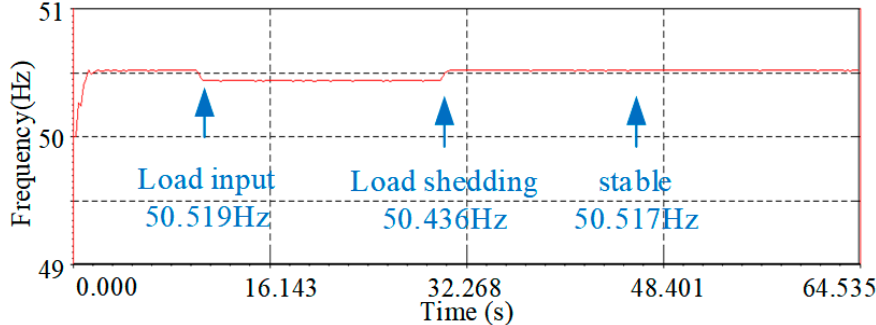

(b)

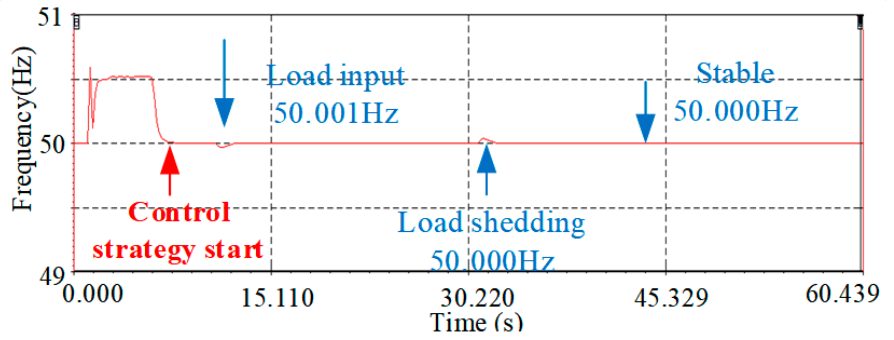

(c)

Figure 14. Experimental results for the frequency waveform (a) with the traditional PI control strategy; (b) with the harmonic and imbalance voltage suppression of multi-inverter parallel VSG; (c) with the harmonic and imbalance voltage suppression of multi-inverter parallel VSG adding a secondary control strategy.

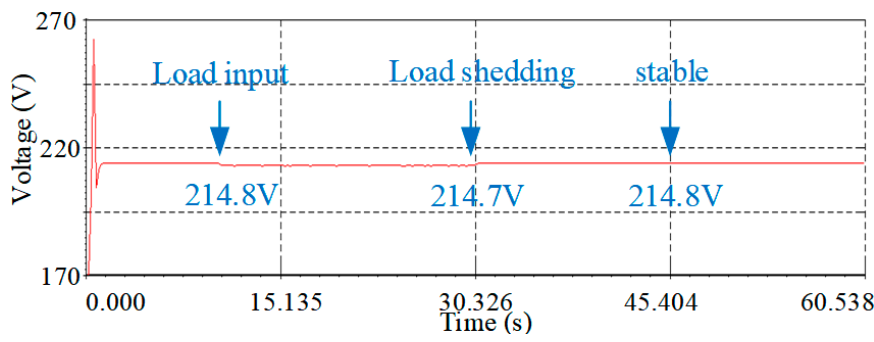

(a)

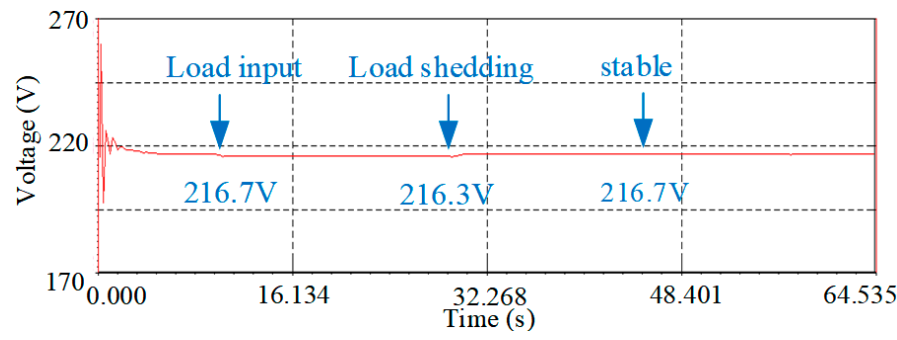

(b)

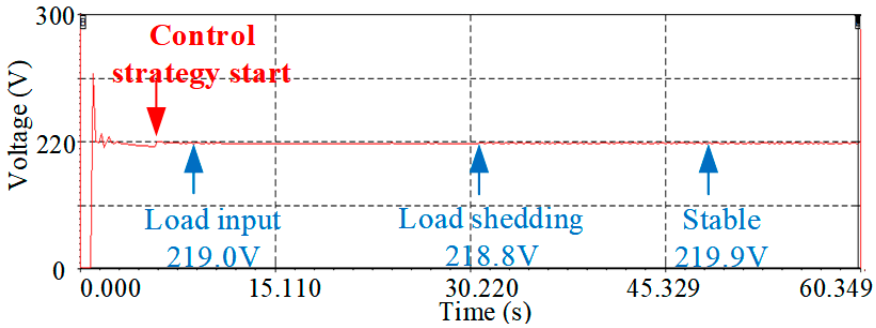

(c)

Figure 15. Experimental results for the waveform of voltage RMS for PCC (a) with the traditional PI control strategy; (b) with the harmonic and imbalance voltage suppression of multi-inverter parallel VSG; (c) with the harmonic and imbalance voltage suppression of multi-inverter parallel VSG adding a secondary control strategy.

As shown in Figure 14, frequency deviates from the standard value, and frequency fluctuation occurs when the system load is altered. In Figure 14a,b, where a secondary control strategy is lacking, when the system is added with a $5 \mathrm{~kW}$ active power load from $10 \mathrm{~s}$ to $30 \mathrm{~s}$, the frequency of the microgrid is reduced from 50.520 to $50.436 \mathrm{~Hz}$ due to the inertia of the VSG. Figure 14c shows that after adding the secondary control strategy, the load switching fluctuation is reduced to $10 \mathrm{~s}$ and $30 \mathrm{~s}$, and the frequency is stable at the rated value $50 \mathrm{~Hz}$. 


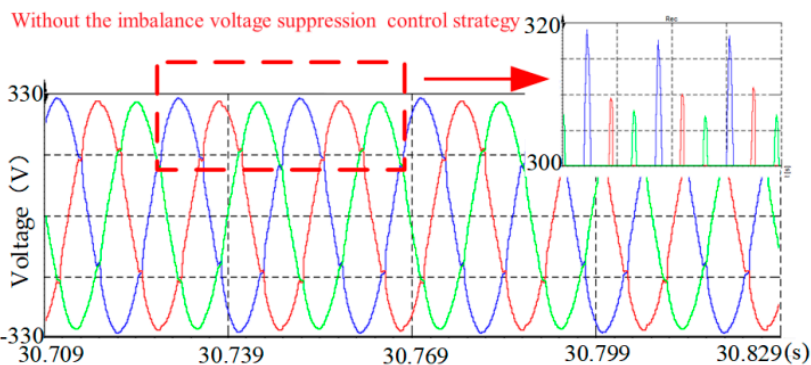

(a)

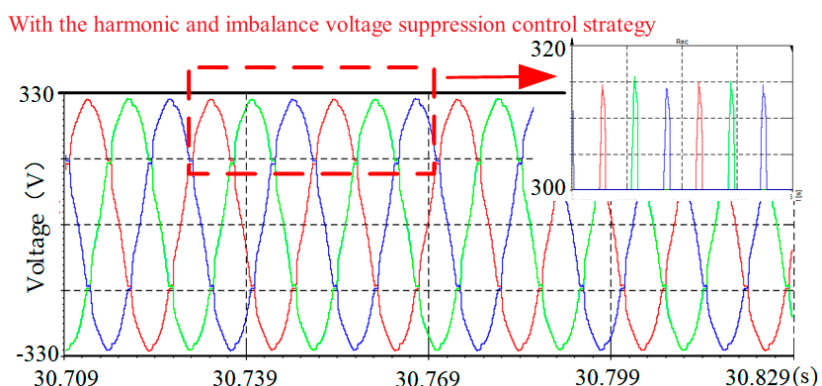

(b)

Figure 16. Experimental results for the voltage waveform of microgrid for PCC point (a) without the imbalance voltage suppression of multi-inverter parallel VSG adding a secondary control strategy; (b) with the harmonic and imbalance voltage suppression of multi-inverter parallel VSG adding a secondary control strategy.

As shown in Figure 15a,b, similar to system frequency control, when the system power fluctuates, the system voltage amplitude will also produce different degrees of fluctuation. Furthermore, according to the inertia of the VSG, when the system power changes significantly, the voltage amplitude will also produce a significant deviation. In Figure 15c, by adding a secondary control strategy, the effective value of the PCC voltage can be stabilized at the rated $220 \mathrm{~V}$, which meets the load power supply requirement, and the system stability voltage control effect is enhanced significantly.

As shown in Figures 11-15, compared with that which only adds harmonics and imbalance control, with secondary control being added to the parallel control of the multiinverter for VSG, it has better control over the frequency and voltage RMS, while performing similarly in terms of imbalance and FFT.

Moreover, in the comparison of the three-phase voltage harmonic imbalance experimental waveforms of Figure 16a,b, the result shows that voltage harmonics and imbalances are significantly eliminated.

From Table 2, the THD of 5th voltage harmonics reduce from $7.1 \%$ to $0.11 \%$, the THD of 7 th voltage harmonics reduce from $4.6 \%$ to $0.08 \%$, and the imbalance ratio of voltage reduces from 5.61 to 0 . It fully demonstrates that the control method proposed in this paper has significant control effects on harmonics and imbalance suppression. The results of the frequency and the RMS of voltage indicate the effectiveness of the proposed secondary control strategy. In addition, compared with the traditional PI control and droop control, the harmonic and imbalance voltage suppression of multi-inverter parallel VSG proposed has damping and inertia, which increases the stability of the frequency and voltage amplitude of the microgrid.

Table 2. Comparison of experimental results.

\begin{tabular}{|c|c|c|c|c|c|c|}
\hline \multirow[t]{2}{*}{ Control Strategy } & \multicolumn{2}{|c|}{$\begin{array}{l}\text { THD of Voltage } \\
\text { Harmonics }(\%)\end{array}$} & \multirow{2}{*}{$\begin{array}{l}\text { Imbalance Ratio } \\
\text { of Voltage }(\%)\end{array}$} & \multirow{2}{*}{$\begin{array}{l}\text { Frequency } \\
\text { (Hz) }\end{array}$} & \multirow{2}{*}{$\begin{array}{l}\text { RMS of Voltage } \\
\text { (V) }\end{array}$} & \multirow{2}{*}{$\begin{array}{l}\text { Inertia and } \\
\text { Damping } \\
\text { (YES/NO) }\end{array}$} \\
\hline & 5th & 7 th & & & & \\
\hline PI control strategy & 7.1 & 4.6 & 5.61 & 50.52 & 214.8 & $\mathrm{NO}$ \\
\hline Comprehensive droop control strategy & 0.08 & 0.13 & 0.05 & 50.00 & 220 & NO \\
\hline $\begin{array}{l}\text { Harmonic and imbalance voltage } \\
\text { suppression of multi-inverter parallel VSG }\end{array}$ & 0.12 & 0.08 & 0.1 & 50.52 & 216.7 & YES \\
\hline $\begin{array}{l}\text { Multi-inverter parallel VSG adding a } \\
\text { secondary control strategy }\end{array}$ & 0.11 & 0.08 & 0 & 50.00 & 219.9 & YES \\
\hline
\end{tabular}

\section{Conclusions}

This paper proposes a harmonic and voltage imbalance suppression comprehensive VSG strategy for distributed control of multi-inverter parallel microgrid. The proposed method is tested on the RT-LAB simulation platform. Experimental results suggest that 
the proposed control strategy can increase the inertia of the microgrid system, improve the influence of frequency and voltage fluctuations on the power quality, and increase the system stability. In addition, the strategy can effectively reduce 5th and 7th harmonic distortion and voltage imbalance, even under non-linear and imbalance load conditions.

The response time of the control strategy proposed in this paper needs to be improved. This work can be further extended for optimizing system parameters through data-driven and reinforcement learning methods, improving the response speed of the control system, and improving power quality.

\begin{abstract}
Author Contributions: Conceptualization, Y.D. and S.M.; methodology, Y.D.; software, H.D.; validation, Y.D., H.D. and S.M.; formal analysis, Y.D. and H.D.; investigation, X.L.; resources, Z.H.; data curation, H.D.; writing-original draft preparation, Y.D.; writing—review and editing, Y.D.; visualization, Y.D.; supervision, S.M.; project administration, S.M.; funding acquisition, Z.H., X.L. and H.D. All authors have read and agreed to the published version of the manuscript.
\end{abstract}

Funding: This work was supported in part by the Liaoning Electric Power Co., Ltd. Science and Technology Project of State Grid under Grant (2021YF-01) and in part by “Liaoning BaiQianWan Talents Program". It was also supported by the Beijing Talents foundation.

Conflicts of Interest: The authors declare no conflict of interest.

\title{
References
}

1. Mehigan, L.; Deane, J.P.; Gallachóir, B.Ó.; Bertsch, V. A review of the role of distributed generation (DG) in future electricity systems. Energy 2018, 163, 822-836. [CrossRef]

2. Ahmad, S.; Mekhilef, S.; Mokhlis, H.; Karimi, M.; Pourdaryaei, A.; Ahmed, T.; Jhuma, U.K.; Afzal, S. Fuzzy Logic-Based Direct Power Control Method for PV Inverter of Grid-Tied AC Microgrid without Phase-Locked Loop. Electronics 2021, $10,3095$. [CrossRef]

3. Ghanbari, A.R.; Karimi, H.R.; Jadid, S. Optimal planning and operation of multi-carrier networked microgrids considering multi-energy hubs in distribution networks. Energy 2020, 204, 117936. [CrossRef]

4. Peng, Y.; Shuai, Z.; Liu, X.; Li, Z.; Guerrero, J.M.; Shen, Z.J. Modeling and stability analysis of inverter-based microgrid under harmonic conditions. IEEE Trans. Smart Grid 2019, 11, 1330-1342. [CrossRef]

5. Burgos-Mellado, C.; Llanos, J.; Cárdenas, R.; Sáez, D.; Olivares, D.E.; Sumner, M.; Costabeber, A. Distributed control strategy based on a consensus algorithm and on the conservative power theory for imbalance and harmonic sharing in 4-wire microgrids. IEEE Trans. Smart Grid 2020, 11, 1604-1619. [CrossRef]

6. Bevrani, H.; Ise, T.; Miura, Y. Virtual synchronous generators: A survey and new perspectives. Int. J. Electr. Power Energy Syst. 2014, 54, 244-254. [CrossRef]

7. Liu, J.; Miura, Y.; Bevrani, H.; Ise, T. Enhanced virtual synchronous generator control for parallel inverters in microgrids. IEEE Trans. Smart Grid 2017, 8, 2268-2277. [CrossRef]

8. Yan, X.; Wang, C.; Wang, Z.; Ma, H.; Liang, B.; Wei, X. A United Control Strategy of Photovoltaic-Battery Energy Storage System Based on Voltage-Frequency Controlled VSG. Electronics 2021, 10, 2047. [CrossRef]

9. Hirase, Y.; Abe, K.; Sugimoto, K.; Sakimoto, K.; Bevrani, H.; Ise, T. A novel control approach for virtual synchronous generators to suppress frequency and voltage fluctuations in Micro-grids. Appl. Energy 2017, 210, 699-710. [CrossRef]

10. Yang, L.; Ma, J.; Wang, S.; Liu, T.; Wu, Z.; Wang, R.; Tang, L. The Strategy of Active Grid Frequency Support for Virtual Synchronous Generator. Electronics 2021, 10, 1131. [CrossRef]

11. Liu, J.; Miura, Y.; Ise, T. Comparison of Dynamic Characteristics Between Virtual Synchronous Generator and Droop Control in Inverter-Based Distributed Generators. IEEE Trans. Power Electron. 2015, 31, 3600-3611. [CrossRef]

12. Du, Y.; Guerrero, J.M.; Chang, L.; Su, J.; Mao, M. Modeling, analysis, and design of a frequency-droop-based virtual synchronous generator for microgrid applications. In Proceedings of the 2013 IEEE ECCE Asia Downunder, Melbourne, Australia, 3-6 June 2013; pp. 643-649. [CrossRef]

13. Jiang, K.; Su, H.; Lin, H.; He, K.; Zeng, H.; Che, Y. A Practical Secondary Frequency Control Strategy for Virtual Synchronous Generator. IEEE Trans. Smart Grid 2020, 11, 2734-2736. [CrossRef]

14. Torres, M.; Lopes, L.A. A virtual synchronous machine to support dynamic frequency control in a mini-grid that operates in frequency droop mode. Energy Power Eng. 2013, 5, 259-265. [CrossRef]

15. Zhang, B.; Yan, X.; Huang, Y.; Liu, Z.; Xiao, X. Stability control and inertia matching method of multi-parallel virtual synchronous generators. Trans. China Electrotech. Soc. 2017, 32, 42-52.

16. Li, Y.; Gao, W.; Yan, W.; Huang, S.; Wang, R.; Gevorgian, V.; Gao, D. Data-driven Optimal Control Strategy for Virtual Synchronous Generator via Deep Reinforcement Learning Approach. J. Mod. Power Syst. Clean Energy 2021, 4, 919-929. [CrossRef]

17. Elbasuony, G.S.; Aleem, S.A.; Ibrahim, A.; Sharaf, A.M. A unified index for power quality evaluation in distributed generation systems. Energy 2018, 149, 607-622. [CrossRef] 
18. Delfino, F.; Rossi, M.; Ferro, G.; Minciardi, R.; Robba, M. MPC-based tertiary and secondary optimal control in islanded microgrids. In Proceedings of the 2015 IEEE International Symposium on Systems Engineering (ISSE), Rome, Italy, 28-30 September 2015; pp. 23-28. [CrossRef]

19. Soni, N.; Doolla, S.; Chandorkar, M. Improvement of Transient Response in Microgrids Using Virtual Inertia. IEEE Trans. Power Deliv. 2013, 28, 1830-1838. [CrossRef]

20. Rosini, A.; Mestriner, D.; Labella, A.; Bonfiglio, A.; Procopio, R. A decentralized approach for frequency and voltage regulation in islanded PV-Storage microgrids. Electr. Power Syst. Res. 2021, 193, 106974. [CrossRef]

21. Ferro, G.; Robba, M.; Sacile, R. A Model Predictive Control Strategy for Distribution Grids: Voltage and Frequency Regulation for Islanded Mode Operation. Energies 2020, 13, 2637. [CrossRef]

22. Grzegorz, B.; Marian, P. Power Theories for Improved Power Quality; China Machine Press: Beijing, China, 2014.

23. Liu, Z.; Xu, X.; Makram, E. Harmonics assessment and mitigation: A case study on an unbalanced stand-alone microgrid integrated with PV. In Proceedings of the 2015 North American Power Symposium (NAPS), Charlotte, NC, USA, 4-6 October 2015; pp. 1-6. [CrossRef]

24. Dong, Y.; Han, Z.; Mu, Y.; Dong, H.; Ma, S.; Cai, Z. Research on micro-grid harmonic suppression controlstrategy based on synchronous inverter technology. Renew. Energy Resources 2020, 38, 1670-1678. [CrossRef]

25. Zhong, Q. Control of Power Inverters in Renewable Energy and Smart Grid Integration; China Machine Press: Beijing, China, 2016.

26. Choudhury, S.R.; Das, A.; Anand, S.; Tungare, S.; Sonawane, Y.D. Adaptive shunt filtering control of UPQC for increased nonlinear loads. IET Power Electron. 2018, 12, 330-336. [CrossRef]

27. Lee, T.; Lee, C.; Cheng, P. An Autonomous Harmonic Filtering Strategy for Distributed Energy Resources Converters in Micro-grid. In Proceedings of the Power Electronics Conference, Bonito-Mato Grosso do Sul, Brazil, 27 September-1 October 2009; pp. 19-25. [CrossRef]

28. Lee, T.; Cheng, P. Design of a New Cooperative Harmonic Filtering Strategy for Distributed Generation Interface Converters in an Islanding Network. IEEE Trans. Power Electron. 2007, 22, 1919-1927. [CrossRef]

29. Shi, R.; Zhang, X.; Liu, F.; Xu, H. A control strategy for unbalanced and nonlinear mixed loads of virtual synchronous generators. Proc. CSEE 2016, 36, 6086-6095. [CrossRef]

30. Zhou, J.; Kim, S.; Zhang, H.; Sun, Q.; Han, R. Consensus-Based Distributed Control for Accurate Reactive, Harmonic, and Imbalance Power Sharing in Microgrids. IEEE Trans. Smart Grid 2016, 9, 2453-2467. [CrossRef]

31. Yin, X.; Lin, Y.; Li, W.; Gu, Y.; Liu, H.; Lei, P. A novel fuzzy integral sliding mode current control strategy for maximizing wind power extraction and eliminating voltage harmonics. Energy 2015, 85, 677-686. [CrossRef]

32. Dong, H.; Yuan, S.; Han, Z.; Zhiyuan, C.; Jia, G.; Yangyang, G. A comprehensive strategy for accurate reactive power distribution, stability improvement, and harmonic suppression of multi-inverter-based micro-grid. Energies 2018, 11, 745. [CrossRef]

33. Li, M.; Huang, W.; Tai, N.; Yang, L.; Duan, D.; Ma, Z. A dual-adaptivity inertia control strategy for virtual synchronous generator IEEE Trans. Power Syst. 2020, 35, 594-604. [CrossRef]

34. Cheema, K.M. A comprehensive review of virtual synchronous generator. Int. J. Electr. Power Energy Syst. 2020, $120,106006$. [CrossRef]

35. Wodyk, S.; Iwanski, G. Three-phase converter power control under grid imbalance with consideration of instantaneous power components limitation. Int. Trans. Electr. Energy Syst. 2020, 30, 12389. [CrossRef]

36. Brandão, D.I.; Ferreira, W.M.; Alonso, A.M.; Tedeschi, E.; Marafão, F.P. Optimal Multiobjective Control of Low-Voltage AC Microgrids: Power Flow Regulation and Compensation of Reactive Power and Unbalance. IEEE Trans. Smart Grid 2020, 11, 1239-1252. [CrossRef]

37. Leitner, S.; Yazdanian, M.; Mehrizi-Sani, A.; Muetze, A. Small-signal stability analysis of an inverter-based micro-grid with internal model-based controllers. IEEE Trans. Smart Grid 2017, 99, 1-10. [CrossRef]

38. Li, Z.; Shahidehpour, M. Small-Signal Modeling and Stability Analysis of Hybrid AC/DC Microgrids. IEEE Trans. Smart Grid 2019, 10, 2080-2095. [CrossRef] 